\title{
Inventory of the Release of Harmful Substances and Evaluation of the Efficiency of Dust and Gas Treatment Plants from Asphalt Concrete Mixing Plants
}

\author{
Keldiyarova Gulmira Farhadovna, Madjidova Tanzila Rahimovna, Sattorov Jafar Jumanazar ug'li \\ Faculty of Geography and Ecology, Samarkand State University, Samarkand, Uzbekistan \\ Email address: \\ guli_d@inbox.ru (K. G. Farhadovna)

\section{To cite this article:} \\ Keldiyarova Gulmira Farhadovna, Madjidova Tanzila Rahimovna, Sattorov Jafar Jumanazar ug'li. Inventory of the Release of Harmful \\ Substances and Evaluation of the Efficiency of Dust and Gas Treatment Plants from Asphalt Concrete Mixing Plants. International Journal \\ of Materials Science and Applications. Vol. 9, No. 5, 2020, pp. 62-65. doi: 10.11648/j.ijmsa.20200905.11
}

Received: March 28, 2020; Accepted: April 24, 2020; Published: November 19, 2020

\begin{abstract}
This article provides time standards and calculation methods for the purpose of studying air pollution from industrial facilities. Calculations of technological equipment and the efficiency of the dust and gas treatment plant. The results of inventory, regulation of emissions of pollutants entering the atmosphere are considered. Questions on the study of equipment for cleaning dust - gas, methods for improving and improving the efficiency of the equipment are highlighted. The methods for determining the composition and quantity of pollutants in the off - gas flows are given: theoretical (balance), computational and analytical (experimental), and reporting and static. The procedure for conducting an inventory of sources of emissions on the territory of the enterprise, the number and composition of emissions of pollutants. Analyses of harmful substances entering the atmosphere from the production of asphalt concrete, measures to improve the efficiency of dust and gas treatment plants were performed. The process of asphalt mixing and production capacity of the enterprise are studied Samarkand asphalt concrete production.
\end{abstract}

Keywords: Asphalt-concrete, Inorganic Dust, Gas, Inventory, Efficiency

\section{Introduction}

Intensive use of natural resources, insufficiently effective cleaning and waste disposal led to disruption of the natural balance in the natural environment of entire geographic regions and individual countries. There is dropped the ability to restore natural resources in large areas. The ecology of some areas of the planet is on the verge of a crisis. [3, 14]

Knowledge of the characteristics of the main methods and methods of purification of atmospheric air, industrial wastewater and soils from various harmful substances at the enterprises of the construction industry is a gap in the environmental issues. At the moment, it is necessary to develop thoroughly the technological schemes of wastewater and air treatment for various construction enterprises. [2]

A large number of small sources can significantly pollute the air. Low sources are understood to be those in which the emission is lower than $50 \mathrm{~m}$, and high sources mean an emission higher than $50 \mathrm{~m}$. Conventionally they call sources that have a temperature of the emitted gas-air mixture higher than $50^{\circ} \mathrm{C}$; at lower temperatures, emissions are considered to be cold. Emissions of enterprises of various industries and transport contain a large number of various harmful impurities.

Hot asphalt plants are similar to each other, although they produce many different types of asphalt surfaces. The difference in the final product is determined by the size and type of sprayer used, as well as the characteristics of the asphalt produced. Hot asphalt for road surfaces is classified by the amount of coarse, coarse and fine-grained filler and mineral dust. The main sources of atmospheric pollution are aerosol emissions from drying drums. $[8,11]$

Asphalt concrete mixes are divided into crushed stone, gravel and sand. Depending on the viscosity of bitumen and the conditions of application, the mixture is classified as hot using viscous bitumens, warm using viscous and liquid bitumens, and cold using liquid bitumens. There are also onetime emissions of aerosols during storage of the filler and its 
treatment of roads, on the territory of the plant, and emissions of odorous resinous substances in places where asphalt is stored and installations for mixing it.

The amount of discharge from the drying drums depends on the size of the filler granules and the type of fuel used. Emissions in the absence of pressure average approximately $20 \mathrm{~kg} / \mathrm{t}$ of filler. Emissions are relatively large particles, the size of more than $50 \%$ of them exceeds $20 \mathrm{mkm}$ and depends on the filler used. Gaseous emissions of sulfur oxides and nitrogen are much less than those of aerosols. $[10,6]$

\section{Methodology}

The following methods are used to determine the composition and amount of pollutants in the exhaust gas streams:

1. theoretical (balance);

2. calculation and analytical (experimental);

3. reporting-static.

The theoretical method allows to establish the composition and quantity of pollutants on the basis of drawing up thermal and material balances of technological processes taking into account the chemical composition and properties of raw materials, fuel, materials, structural and geometric features of units, technological parameters, processes that ensure maximum performance of units and data on specific emissions of pollutants of the operated equipment.

Samarkand State Unitary Enterprise for Current Road Useis located in the village, Farhad in Samarkand. The main activity of the enterprise is the production of asphalt-concrete mix and reinforced concrete products. The production capacity of the enterprise is 200 thousand tons per year of asphalt concrete mix, and production of 10 thousand $\mathrm{m}^{3} /$ year of reinforced concrete structures. [5]

\section{Alanis}

Asphalt mixer brand AMMAN has a capacity of 160 tons in one hour. The main activity of Samarkand state Unitary Enterprise for Current Road Use is the production of asphalt mix and the manufacture of concrete products.

38 sources of emissions of pollutants into the atmosphere were identified, of which 12 were organized. On the territory of the Samarkand State Unitary Enterprise for Current Road use. $[1,13]$

The release of pollutants occurs as a result of the work of the following equipment, or technological operations;

Unit of dumping PGS dump trucks into the bunker of the reloading device- 1 pc. $[4,7]$

PGS filling unit from transfer hopper to belt conveyor No. 1,1 pc. crushing and screening shop. The source of the release of inorganic dust $\left(\mathrm{SiO}_{2} 20-70 \%\right)$ is the process of unloading wet raw materials with a dump truck into the bunker of handling equipment. The volume of the discharged RMT is 110,5 thousand $\mathrm{m}^{3} /$ year or 210,000 tons/year. The duration of the dump truck unloading processes, with an average productivity of the dumping unit of 162 tons/hour, is

\section{1,300 hours/year.}

The main activity of the Samarkand asphalt concrete plant is the production of asphalt concrete mix and the production of reinforced concrete izzheliy. The production activity of the enterprise is carried out on one industrial site, in the following workshops and sections; administrative and household buildings; crushing and sorting shop; asphalt mixing shop; bitumen storage; concrete mixing unit; cement warehouse; boiler room; reinforcement shop; mechanical shop; garage; shop of reinforced concrete products; fuel and lubricants

1. Calculation of dust emissions unlimited in the process of dumping the RTM from dump trucks, is carried out according to the formula:

$$
\mathrm{q}=\mathrm{K}_{1} * \mathrm{~K}_{2} * \mathrm{~K}_{3} * \mathrm{~K}_{4} * \mathrm{~K}_{5} * \mathrm{~K}_{7} * \mathrm{~B} * \mathrm{G} * 106 / 3600, \mathrm{~g} / \mathrm{s}
$$

where,

$\mathrm{K}_{1}$-weight fraction of the dust fraction in the rock is 0,04 ;

$\mathrm{K}_{2}$-fraction passing into aerosol volatile dust- 0,02

$\mathrm{K}_{3}$-coefficient taking into account wind speed-1,0

$\mathrm{K}_{4}$-coefficient, taking into account the closeness of the node- 0,2 .

$\mathrm{K}_{5}$-coefficient taking into account the moisture content of the material-0,4;

$\mathrm{K}_{7}$-coefficient taking into account the size of the material 0,01 ;

B-coefficient taking into account the height overfilling 0,4 ;

G-performance of the filling unit $-167 \mathrm{t} / \mathrm{g}$

$$
\begin{gathered}
\mathrm{q}=0,04 * 0,002 * 1,0 * 0,2 * 0,01 * 0,4 * 0,5 * 162 * \\
106 / 3600=0,0144 \mathrm{~g} / \mathrm{s} .
\end{gathered}
$$

The estimated power of inorganic dust emission from dump truck unloading processes is;

$$
\mathrm{M} \text { - inorganic dust }=0,0144 \mathrm{~g} / \mathrm{s} \text {. }
$$

The source of inorganic dust emission is the mixing unit from the hopper of the reloading device to the No. 1 belt conveyor. The volume of the $\mathrm{CBC}$ is 109.95 thousand $\mathrm{m}^{3} /$ year or $208905 \mathrm{t} /$ year. The duration of the filling process of the ASG, with an average productivity of the filling unit $115 \mathrm{t} /$ hour, is 1820 hours/year. [15]

2. Calculation of dust emission unorganized in the process of pouring the ASG from the hopper of the reloading device to the conveyor belt No. 1 is carried out according to the formula:

$$
\mathrm{q}=\mathrm{K}_{1} * \mathrm{~K}_{2} * \mathrm{~K}_{3} * \mathrm{~K}_{4} * \mathrm{~K}_{5} * \mathrm{~K}_{7} * \mathrm{~B} * \mathrm{G} * 106 / 3600, \mathrm{~g} / \mathrm{s}
$$

where,

$\mathrm{K}_{1}$-weight fraction of the dust fraction in the rock is 0,04 ;

$\mathrm{K}_{2}$-fraction passing into aerosol volatile dust- 0,02

$\mathrm{K}_{3}$-coefficient taking into account wind speed-1,0

$\mathrm{K}_{4}$-coefficient, taking into account the closeness of the node-0,2.

$\mathrm{K}_{5}$-coefficient taking into account the moisture content of the material- 0,4 ; 
$\mathrm{K}_{7}$-coefficient taking into account the size of the material 0,01 0,1 ;

B-coefficient taking into account the height of the pour -

G-productivity of the site $-115 \mathrm{t} / \mathrm{g}$

$$
\begin{gathered}
\mathrm{q}=0,04 * 0,002 * 1,0 * 0,2 * 0,01 * 0,4 * 0,1 * 115 * \\
106 / 3600=0,002044 \mathrm{~g} / \mathrm{s} .
\end{gathered}
$$

The estimated power of inorganic dust emission from the mixing process of the ASG from the hopper of the transfer device is not:

$$
\mathrm{M} \text { - inorganic dust }=0,002044 \mathrm{~g} / \mathrm{s} .
$$

Inorganic dustB $=\mathrm{C} * \mathrm{Q}: 1000=61,7 * 4,4: 1000=0,271 \Gamma / \mathrm{c}$.

$$
\begin{gathered}
\text { Inorganic dustM }=\mathrm{B} * \mathrm{~T} * 3600: 10^{6}=0,271 * 1300 * \\
3600: 10^{6}=1,26 \mathrm{t} / \mathrm{y} .
\end{gathered}
$$

After cleaning, the inorganic dust enters the atmosphere: Inorganic dust $\mathrm{B}=\mathrm{C} * \mathrm{Q}: 10^{3}=9,3 * 3,8: 10^{3}=0,035$ г/c. $\mathrm{M}=\mathrm{B} * \mathrm{~T} * 3600: 10^{6}=0,035^{*} 1300 * 3600: 10^{6}=0,163 \mathrm{t} / \mathrm{y}$

The effectiveness of the dust-cleaning gas installation is determined by the formula:

\begin{tabular}{|c|c|c|c|c|c|c|c|}
\hline Name of pollutant & $\begin{array}{l}\mathrm{MPC} \\
\mathrm{mg} / \mathrm{m}^{3}\end{array}$ & $\begin{array}{l}\text { The mass of } \\
\text { emissions (before } \\
\text { cleaning) } \mathrm{mg} \backslash \mathrm{m}^{3}\end{array}$ & $\begin{array}{l}\text { The mass of } \\
\text { emissions (before } \\
\text { cleaning) } \mathrm{g} / \mathrm{s}\end{array}$ & $\begin{array}{l}\text { The mass of } \\
\text { emissions (before } \\
\text { cleaning) } t / y\end{array}$ & 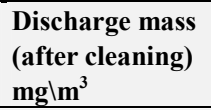 & $\begin{array}{l}\text { Discharge mass } \\
\text { (after cleaning) } \\
\text { g/s }\end{array}$ & $\begin{array}{l}\text { Discharge mass } \\
\text { (after cleaning) } \\
\text { t/y }\end{array}$ \\
\hline $\begin{array}{l}\text { Dust inorganicSiO } \mathrm{SiO}_{2} 20- \\
70 \%\end{array}$ & 0,3 & 61,7 & 0,27 & 1,26 & 9,3 & 0,035 & 0,163 \\
\hline \multicolumn{8}{|c|}{ Efficiency of dust and gas treatment plant } \\
\hline The status of the installation & & $87,1 \%$ & & Expected results: & & $98,5 \%$ & \\
\hline
\end{tabular}

$$
\eta_{1}=\frac{\left(M_{b}\right) 1,26-\left(M_{e}\right) 0,163}{\left(M_{b}\right) 1,26} \times 100=87,1 \%
$$

$\mathrm{M}_{\mathrm{b}}$ is the initial concentration of $\mathrm{mg} / \mathrm{m}^{3}$; $\mathrm{M}_{\mathrm{e}}$-final concentration $\mathrm{mg} / \mathrm{m}^{3}$.

Table 1. The list of pollutants and the efficiency of the dust-free gas cleaning plant.

\section{Results and Discussion}

The table 1 shows the results of the gas cleaning plant which is installed in the asphalt mixing shop. The most accurate and reliable way to determine the amount of dust is the gravimetric method: when air is sucked, the dust is collected on a suspended filter or other separation device and weighed. The analyses were made in the research and testing laboratory of Samarkand state Institute of architecture and construction. The study showed that the efficiency of the installation is $87 \%$. [12]

$\Pi$ and $\mathrm{S}$ - the perimeter and cross-sectional area of the hole (slot);

$\mathrm{d}_{\text {экв }}$ - equivalent diameter of the hole (slot).

The resistance of the gas-liquid layer approximate is taken to be equal to the static pressure of the layer:

$$
\Delta P 2=g \rho ж h 0=g \rho_{\Pi} \mathrm{h}_{\Pi}
$$

During operation the production of bricks will form the following types of waste primary production: overburden, defective brick mounding Department, a defective brick drying Department, defective burnt bricks of waste coal ash. Coal ash meets the above requirement, as many cement plants use ash as an additive in clinker grinding. (V. F. Maximov, I. V. Wolf. Cleaning and recovery of industrial emissions. Moscow. "Lenna industry" 1981. The use of waste power plants allowed to increase the production of bricks grades 125 and 100, significantly improve its presentation and $30 \%$ reduce the amount of marriage. (Chistyakov B. Z. the use of industrial waste in construction. L., 1977. 142c.) Improving the efficiency of industry it is necessary to consume unconventional energy. Solar energy the direction of non-traditional energy, based on the direct use of solar radiation to produce energy in any form.

\section{Conclusion}

Work on the inventory of emission sources of pollutants was complex and was carried out in strict accordance with the regulatory documents defining and regulating the composition, structure and volume of these works. According to the results of the inventory, identified; emission sources 50 , emission sources-38, of which organized-12, equipped with PGOU-5, pollutants-12.

Pollutant uptake -36,789033t/year. [9]

The gross emission of pollutants into the atmosphere is 11,462165 tons/year, emissions from mobile sources amount to 101,078142 tons/year. Calculation analysis of surface concentrations of harmful substances are generated by production emissions showed that their contribution to the level of air pollution is insignificant and does not exceed the established quotas at the border of the production site of the open pit and the plant.

The proposed bubble absorber with the establishment of an asphalt concrete plant, the effectiveness of the dust of the gas treatment plant asphalt concrete plant increases from $87 \%$ to $99 \%$.

\section{References}

[1] G. Keldiyarova. Assessment of the efficiency of gas and dust cleaning systems in asphalt-concrete plants. International Journal of Applied Research. 2019 y-23p.

[2] Boboev, G. F. Keldiyarova Allocation of harmful substances from brick factories located in the Samarkand region. 2018 y, $62 \mathrm{p}$. 
[3] I. Yu. Popovich, I. L. Revutskaya.- The impact of road transport on the quality of atmospheric air in Birobidzhan 2018, 106 pages.

[4] Regulations on State environmental expertise. Approved by Resolution of the Cabinet of Ministers of the Republic of Uzbekistan No. 491 of December 31, 2001.

[5] V. F. Maksimov, I. V. wolf " Cleaning and recovery of industrial emissions"Moscow. "Forest industry" 1981.

[6] M. I. Birger, A. Yu. Walberg, B. I. Myagkov, V. Yu. Padva, A. A. Rusanov. "Handbook of dust and ash collection" Moscow. Energoatomizdat. One thousand nine hundred eighty three.

[7] V. LEITI Definitions of air pollution in the atmosphere and on the desktop. - L.: Chemistry, 1999. 23 p.

[8] Article. "Environmental monitoring and its tasks." L. Tagirov, D. Mukhamedzhanova. Ecological Bulletin of Uzbekistan. 2016 year. 9,13 .

[9] V. F. Maksimov (1981). "Cleaning and recovery of industrial emissions". Moscow. "Forest industry".
[10] M. I. Birger and others. (1983). A "Handbook of dust and ash collection” Moscow. Energoatomizdat.

[11] A. A. Rusanov Under the general editorship. Handbook of dust and collection.

[12] Boboyev S. M., Keldiyorova G. F. (2018). Emission of harmful substances from brick factories located in the Samarkand region. Journal of Samarkand state university $p$ 56-58.

[13] Popova I. Y., Revuskaya I. L. (2018). The impact of road transport on the atmospheric air quality of the citybook. Moscow p 106.

[14] Hygienic classifier of toxic industrial waste in the conditions of the Republic of Uzbekistan. SanPiNRUz. №0128-02. Tashkent, 2002 22, 123, 189 p.

[15] Munn R. E. Global environmental monitoring system. SCOPE, rep. 3. Toronto. 